\title{
Research Conception of Children's Education Development under the Cooperation Between Yunnan and Shanghai
}

\author{
Xiaodong Ding ${ }^{1, \text { a }}$ \\ ${ }^{1}$ School of Law and Public Administration of Qujing Normal University, Qujing, Yunnan Province, \\ China
}

a1971161842@qq.com

\begin{abstract}
Keywords: Cooperation Between Yunnan And Shanghai, Children's Education, Conception.
\end{abstract}
\begin{abstract}
Under the background of implementing Outline of National Medium and Long-term Educational Reform and Development, children's education has become the focus of the education sector in China. Children's education in Yunnan is backward. Thus, it should draw lessons from the advanced experience of Shanghai, so that it will promote the development of children's education in Yunnan. Four aspects, namely children's education theory, teachers of children's education, children's education curriculums and the specific implementation of the reform and development of children's education in Yunnan, constitutes the main content of children's education development. Although Research on the development of children's education under the cooperation between Yunnan and Shanghai is only a kind of conception and exchange between the eastern and western universities, it can get some enlightenment from it.
\end{abstract}

\section{Introduction}

It is stipulates in Convention on Children's Rights (1989) that a child means any person under 18 years old. In Law on Protection of Minors of the People's Republic of China (1991), citizens under the age of 18 refer to minors. Since then, the age of children has expanded to 18 years old. In this paper, children mainly refer to those from 3 years old to 12 years old. They are in pre-school and primary school. Taking an example of Research on the development of children's education under the cooperation between Yunnan and Shanghai, this paper studies on the conception of cooperation the eastern and western universities.

National Medium and Long-term Educational Reform and Development (2010-2020) puts forward the basic requirement of popularizing pre-school education. Children's education has become the focus of education in our country. Children's education in is relatively backward. How to promote the good and fast development of Yunnan's children's education requires in-depth analysis of the plight and potentiality of children's education in Yunnan and the advanced experience learnt from developed areas. Firstly, we should realize the current situation of children's education in Yunnan. Generally, children's education in Yunnan is backward. And its development is very uneven. The gap between urban and rural areas is large. Children's admission rates in remote areas and ethnic areas are still very low. The status of such children's education is a naked challenge to the educational equity and social equity. At the same time, children's education in Yunnan has many fundamental problems, which is worthy of introspection. For example, can children's education be guided by scientific conception of children? Can education and teaching activities well promote the healthy development of children's physical and mental health? Can children's culture be consciously built? Secondly, we should pay attention to the opportunity of children's education in Yunnan. The compulsory education in Yunnan has been continually strengthened. The construction of new socialist countryside has been lasting. China has also put forward a blueprint of basic universal pre-school education. In particular, Yunnan generally popularized the one-year-education before preschool year education in 2012. And it will popularize the three-years-education before preschool year education in 2020.1000 rural public kindergartens will be gradually built. And 200 of them will be built as demonstration kindergartens. [1] In addition, Yunnan has the advantages of national culture and the corresponding potential development in terms of children's education. All of these will provide good historical 
opportunities and conditions for the development of children's education in Yunnan. Thirdly, we should draw lessons from the advanced experience of Shanghai on children's education to promote the development of children's education in Yunnan. Shanghai children's education is in the forefront of our country. Among them, Shanghai Normal University draws on the experience of Japanese children's study and focuses on the long-term commitment to develop and build a new discipline of Paedology. Its innovative research results will provide theoretical guidance for the development of children's education in Yunnan. Carrying out research on the development of children's education under the cooperation between Yunnan and Shanghai will benefit the children of Yunnan, especially those in the remote areas of Yunnan Province. And it will have great epochal and practical significance.

\section{The Target and Content of Cooperation}

For Yunnan, the achievements of Shanghai children's learning innovation researches can be referred to promote the development of children's education in Yunnan. Specifically, from the perspective of theory, we can conclude the successful practice and experience of children's education in Yunnan; from the perspective of strategy, we can mine the resources of national culture and carry out children's education reform; and from the perspective of practice, we can construct the new mode of village to city and coordinated development. For Shanghai, the outcomes of children's education can be expanded to the border areas to enrich the connotation of the study on children and form children's study of Japan - Shanghai - Yunnan and its development path.

The specific implementation of children's education theory, teachers of children's education, children's education courses and Yunnan children's education reform and development involves the theoretical and practical development of children's education in Yunnan. And teachers of children's education, children's education courses are the key issues, which together constitutes the main content of cooperation in this research.

A study on the theory of children's education in Yunnan. Firstly, the combination of history and reality is expected. Through the analysis of Yunnan children's education history and the basis of ecological, social, economic and cultural situation, we can analyze the value and significance of children's education from the perspective of culture. By analyzing and summarizing the features and experience of children's education in Yunnan, the national features of children's education in Yunnan will be found and its potential advantages will be explored. Secondly, the combination of cultural interpretation and empirical research is expected. Children's education and research should not only use observation, measurement, evaluation and logical reasoning, but also rely on the interpretation of national culture which can reflect the meaning of the phenomenon of children's education. These will make children's education and research results have cultural and national features. In the specific study, we should not only make appropriate empirical studies, but also use qualitative research methods and return to the real situation with depth interviews, showing its original appearance. Thirdly, the combination of children's education experience in Shanghai and the actual situation of that in Yunnan is expected. Through the exchange and cooperation, we should actively introduce and learn the advanced education ideas about paedology and other advanced educational philosophy of children's education in Shanghai. For example, the innovation achievements of paedology of Shanghai Normal University mainly include the following several aspects, to adhere to the principle of children-oriented from the perspective of theory; to grasp the international view from the perspective of research; the tendency of local action from the perspective of superior features. While actively carrying out international cooperation on children's education, Shanghai should also strengthen the education of national spirit and cultural tradition. This inspires us that we can draw on the children-oriented position and focus on the nationality of children in Yunnan; learn from the experience of combining international vision and regional culture in Shanghai; improve the children's education value of ethnic culture in Yunnan; draw on the tendency of local action; cultivate children's education with Yunnan features. There is a huge gap in the educational ideology, research consciousness and ability, cooperation and exchange of children's education in Yunnan. Specifically, the implementation of the children-oriented educational ideology is not enough; teachers' research on 
children's education is not enough; the cooperation of universities and primary school and kindergartens is not enough. Therefore, the advanced philosophy and advantages of children's education in Shanghai is urgently needed in Yunnan. While drawing on the advanced ideas and experience of children's education in Shanghai, the in-depth exploration into the specialty of Yunnan children's education is also expected which will help to solve the practical problems of Yunnan children's education. Thus, the innovative philosophy of children's education with Yunnan's actual situation and contemporary advanced education philosophy will not only contribute to the solid theoretical foundation for the development of children's education in Yunnan, but also promote the new research fields and construction path of subjects, enhance the theoretical level of children's education, refine the features of children's education, so that it will expand the education space of Yunnan.

On teachers' training of children's education in Yunnan. Undergraduates' majors of preschool education and primary education have been included in the higher education system. The teachers training of Shanghai children's education has achieved informationization, internationalization and integration system of pre-service and in-service. However, the children's education level in Yunnan is relatively backward. Then, what is gap between the quantity, quality and level of primary school and kindergarten teachers in Yunnan and the requirements of its children's education development? Based on the teachers' nature and professional requirements quality and drawing lessons from the teachers training experience of Shanghai children's education, the problem of how to develop and implement an approach with feasibility to make up the gap is to be solved. Under the background of deepening the reform of basic education in China, scientific orientation of teachers training in Yunnan is expected, as well as the exploration into the training mode of teachers for children's education which is in line with the actual situation of Yunnan, the reform of practice teaching system of teachers' training, the comprehensive practice teaching activities which return to children's education life, the teachers' occupation emotion and belief education. All these will contribute to the solution of the current dilemma of teachers' professionalization and the promotion of teachers' professional development, so that teachers' for children's education will be qualified with strong teaching ability, research competence and management skills.

On the curriculum reform and development of Yunnan children's education. Since the twentieth century, the education reforms among the world have lasted for a long time. In western countries, there are three educational curriculum reforms in the twentieth century, including the children-oriented curriculum experiment. After the founding of China, our country has carried on the curriculum reform for eight times. The lasted children's education curriculum reform began in 1990s. This reform advocates that education should return to children's life. However, the children's life is deeply marked by the stigma of national culture, which reveals that the study of children's life can be studied from the perspective of national culture in Yunnan and the problems of children's curriculum reform and development can be studied. Yunnan should make use of the advantages of national and cultural resources to transform the perspective of children's education and expand the space of children's education. The cultural character transformation of children's education and research will become a new point in education circles of both Yunnan and Shanghai. This requires dealing with several kinds of relationship. Firstly, we should handle the relationship between one and many. Only we respect and understand other national culture, there will be the harmonious coexistence of different ethnic groups and the local cultural security will have fundamental guarantee. [2] This shows that the colorful ethnic culture in Yunnan will not be the problem of children's education curriculum reform and development. It has become the advantage of the reform and development resources of children's education curriculums. This will provide a basis for solving the relationship between the native ethnic culture and other ethnic groups in Yunnan and point out the direction of children's education. Secondly, we should deal with the relationship between national culture and children culture. Not all of the elements of national culture are suitable for the curriculums of children's education. Only the excellent ones and the typical elements that match the characteristics of children culture are suitable to be materialized in children's education courses. Thus, the children's individual experience and the national culture can be constructed at the same time. In the selection 
process, four kinds of contents can be selected: the outstanding national culture; typical elements of excellent national culture; typical elements that are consistent with the children's features among excellent national culture; the appropriate way to show the content to children. Thirdly, we should deal with the relationship between theoretical value and practical value, social benefit and economic benefit. In terms of the curriculum reform and development of children's education, we should not only construct the children's education curriculum theory with the features of Yunnan. More importantly, from the point of ethnic minorities, we can adopt the interdisciplinary research methods to study on children's education curriculums, expand and deepen the application research on children's education. The outcomes of theoretical research can be applied in children's practice curriculums in Yunnan. In addition, we should fully tap the value of ethnic culture on children's education, guide the cultural consumption in the field of children's curriculum development in Yunnan and pay attention to the corresponding commercial value, so that we will achieve the social and economic benefits.

On the implementation of children's education development in Yunnan. The contents from the above three aspects will ultimately contribute to the completion of Implementation plan on children's education development in Yunnan. The implementation plan mainly includes the economic development and education investment, the philosophy of children education, the location of children's education (especially preschool education), the scale and reform steps, the training of teachers of children's education, the courses and development of children's education, the reform and development mode of children's education in Yunnan. In the study, we should pay attention to the representativeness of investigation, the differences of regions and nations and the scientificity of data; strengthen the exploration into Yunnan minority and private primary schools and kindergartens; make the comparative studies carried out in Yunnan and Shanghai. Therefore, we can provide consulting services for the Yunnan children's education development. In addition, we should also adopt the combination of the typical analysis and universal rules. Typical investigations should be done from the following aspects, primary school and kindergarten, public and private schools, the Han nationality and ethnic minority areas, the less developed regions and developed regions in Yunnan, Shanghai and Yunnan, the teachers of children's education and curriculums, etc. Based on the typical analysis and comparative study, we can further explore the universal rules, not only to formulate and complete the implementation plan of children's education development in Yunnan, but also to make the outcomes of the cooperation project significant.

\section{The Basis and Ideas of Cooperation}

The basis of cooperation. Shanghai has the ability and responsibility to support Yunnan. Yunnan has unique and rich cultural resources whose value in children's education has been concerned by the educational sectors of Shanghai. The important thing is that their cooperation is a win-win way. The developed Shanghai and less developed Yunnan have broad prospects for cooperation. The sharing of eastern and western resources and complementary advantages will be a new development momentum. The cooperation between Yunnan and Shanghai in studying children's education is one kind of the valuable specific cooperation, which will gain the expected achievements.

The ideas of cooperation. On the one hand, Shanghai can provide theoretical guidance and material analysis for studying the problems of the development of children's education. Shanghai can also provide advice on the overall design of cooperation projects, determine the direction and focus of the construction of cooperation projects and guide the relevant professional construction work. On the other hand, Yunnan can assign personnel to Shanghai Higher Education Institutes for learning, consultation, cooperation and the completion of the main construction tasks.

Research on the development of children's education under the cooperation between Yunnan and Shanghai is only a conception of cooperation and exchange between the eastern and western universities and colleges. From this project, we can conclude some enlightenment. Firstly, by using the platform of the cooperation between Shanghai and Yunnan, it can provide guarantee for the implementation of the project. Secondly, in accordance with the principle of common concern, complementary advantages, mutual benefits and win-win outcomes, it can select the cooperative 
projects. The development of children's education is concerned by both Yunnan and Shanghai. In terms of children's education, Yunnan has the advantages of national and cultural resources while Shanghai has rich theories and experience. It can provide each other more fresh elements to achieve the win-win outcomes. Thirdly, by adopting specific projects, it can promote the cooperation and communication between the eastern and western universities and colleges. Based on these specific projects which can be a starting, it can gradually expand the field of cooperation and exchanges, and strive to improve the level of cooperation and exchanges in personnel training, academic research and social services.

\section{Acknowledgement}

Project Fund: This project is the medium-term implementation assessment of Outline for Medium and Long-term Educational Reform and Development in Qujing, Yunnan Province and the latter implementation assessment of The Twelfth Five-year Plan of Educational Development in Qujing and this project is supported by Foundation for Innovation Team of Researching on Teachers' Training for Children's Education of Qujing Normal University.

\section{References}

[1] Xia Luo. Thousands of rural kindergartens will be built to speed up the popularization of basic pre-school education in our province. [DB/OL].http://news.163.com/10/0301/09/60MA2I5Q000146 BB.html

[2] Zong-shun Zhu. Misunderstanding of Cultural Security: A Comment on The Choice About The Value Of Children Education [J]. EARLY CHILDHOOD EDUCATION (EDUCATIONAL SCIENCES), 2006 (2): 14. 